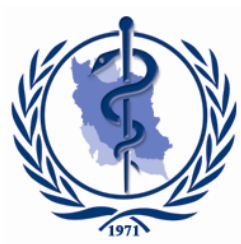

$\underline{\text { Review Article }}$

\title{
Comparing the Efficacy of Angiotensin Converting Enzyme In- hibitors with Calcium Channel Blockers on the Treatment of Di- abetic Nephropathy: A Meta-Analysis
}

\author{
*Zhaowei ZHANG ${ }^{1}$, Chunlin CHEN ${ }^{2}$, Shiwen $L V^{1}$, Yalan ZHU ${ }^{1}$, Tianzi FANG ${ }^{1}$ \\ 1. Department of Pharmacy, Jin Hua Municipal Central Hospital, Jin Hua 32100, China \\ 2. College of Chemistry and Bio-Engineering, Yi Chun University, Yi Chun 336000, China \\ *Corresponding Author: Email: quhaizhijia@163.com
}

(Received 21 Mar 2018; accepted 11 Jun 2018)

\begin{abstract}
Background: The angiotensin-converting enzyme inhibitors (ACEIs) could improve the symptoms of diabetic nephropathy. Whether the calcium channel blockers (CCBs) could be as effective as ACEIs on treating diabetic nephropathy is controversial. Here, we aimed to compare the efficacy of ACEIs with CCBs on the treatment of diabetic nephropathy by performing a meta-analysis of randomized controlled trials (RCTs).

Methods: The Pubmed, Medline, Embase and The Cochrane Database were searched up to July 2017 for eligible randomized clinical trials studies. Effect sizes were summarized as mean difference (MD) or standardized mean difference (SMD) with 95\% confidence intervals $(P$-value $<0.05)$.

Results: Seven RCTs involving 430 participants comparing ACEIs with CCBs were included. No benefit was seen in comparative group of ACEIs on systolic blood pressure ( SBP ) ( $\mathrm{MD}=1.05 \mathrm{mmHg}$; 95\% CI: -0.97 to 3.08, $P=0.31)$, diastolic blood pressure (DBP) $(\mathrm{MD}=-0.34 \mathrm{mmHg}$; $95 \% \mathrm{CI}:-1.2$ to $0.51, P=0.43)$, urinary albumin excretion rates (UAER) $(\mathrm{MD}=1.91 \mu \mathrm{g} / \mathrm{min} ; 95 \% \mathrm{CI}$ : -10.3 to $14.12, P=0.76), 24$-h urine protein (24-UP) (SMD $=-0.26$; $95 \%$ CI: -0.55 to $0.03, P=0.08$ ), glomerular filtration rate (GFR) (SMD $=0.01 ; 95 \% \mathrm{CI}$ : -0.38 to $0.41, P=0.95)$. On safety aspect, the risk of adverse reactions between ACEIs group and CCBs group are similar $(\mathrm{RR}=1.18$; $95 \% \mathrm{CI}: 0.61$ to $2.28 ; P=0.61)$.

Conclusion: Both ACEIs and CCBs could improve the BP, UAER, 24h-UP, and GFR of diabetic nephropathy to a similar extent.
\end{abstract}

Keywords: Diabetic nephropathy; Angiotensin converting enzyme inhibitors; Calcium channel blockers; Metaanalysis

\section{Introduction}

Diabetic nephropathy (DN) is a major complication of diabetes. It is the main common cause of end-stage kidney disease (ESKD) (1). DN often develops with macrovascular disease including cardiovascular, cerebrovascular, and peripheral arterial diseases with a higher risk of morbidity and mortality (2). The mechanism of DN is very complex due to inflammation, hemodynamic effects and genetic predispositions which manifest in fibrotic lesion and eventually irreversible organ damage (3). Microalbuminuria is generally considered the earliest marker for the development of diabetic nephropathy (4). Some patients with microalbuminuria will progress to macroalbumi- 
nuria and eventually to ESRD (5). Moreover, Glomerular filtration rate (GFR), a critical index for assessment of renal dysfunction, starts to mildly decreases during the phase of microalbuminuria (6). As the increasing number of $\mathrm{DN}$ individuals, the development of cost-effective therapeutic strategies for these individuals is a crucial public health concern (7). The treatment of patients with DN can be divided into 4 major arenas: cardiovascular risk reduction, glycemic control, blood pressure control and inhibition of the RAS (8).

Angiotensin-converting enzyme inhibitors (ACEIs) is one type of antihypertensive drugs. It lower intraglomerular pressure via inhibiting renin angiotensin aldosterone system (RAAS). In addition, ACEIs has superior cardioprotective effects compared with other antihypertensive drugs (6). Therefore, ACEIs have been considered as the standard care in patients with diabetic nephropathy recommended by The American Diabetic Association (9). Calcium channel blockers (CCBs) could decrease albuminuria in patients with incipient diabetic nephropathy, but there are no guidelines recommended that CCBs is the standard care in treating DN (10-12).

Less is known about whether the ACEIs or CCB could be better to patients with DN. Therefore, the purpose of this meta-analysis was to compare ACEIs with $\mathrm{CCBs}$ on reducing albuminuria and improving GFR of patients with DN.

\section{Methods}

\section{Search Strategy}

We conducted search of PubMed, Medline, EMBASE and COCHRANE (from Jan 1992 to Jul 2017) to identify all trials published in English involving the following search terms: ("Angiotensin Converting Enzyme Inhibitors") (Mesh) OR alacepril OR benazepril OR captopril OR ceronapril OR cilazapril OR enalapril OR fosinopril OR perindopril OR ramipril OR delapril OR imidapril OR moexipril OR spirapril OR rentiapril OR trandolapril OR zofenopril OR libenzapril OR quinapril OR lisinopril AND ("Calcium
Channel Blockers") (Mesh) OR amlodipine OR amrinone OR anipamil OR benidipine OR bepridil OR berbamine OR cinnarizine OR diltiazem OR devapamil OR darodipine OR dotarizine OR efonidipine OR emopamil OR felodipine OR fendiline OR flunarizine OR gallopamil OR isradipine OR lacidipine OR lercanidipine OR lidoflazine OR lomerizine OR manidipine OR mepirodipine OR mibefradil OR monatepil OR nicardipine $\mathrm{OR}$ nifedipine $\mathrm{OR}$ nilvadipine $\mathrm{OR}$ nimodipine OR nisoldipine OR nitrendipine OR pranidipine OR prenylamine OR sesamoid OR verapamil OR oxodipine OR perhexiline AND nephropathies OR diabetic nephropathy OR diabetic kidney disease AND random OR randomized OR randomised OR double blind OR placebo OR controlled OR randomized controlled trial.The protocol with details for this metaanalysis was published on the PROSPERO website (http://www.crd.york.ac.uk/PROSPERO/), (PROSPERO CRD 42016048199) ahead of the initiation of the literature search.

\section{Study Selection}

Two investigators selected the studies independently and resolved any conflicts through discussion. The inclusion criteria for this metaanalysis were as follows: 1) study design: controlled or parallel RCT designs 2) population: patients with hypertension, diabetes and microalbuminuria or macroalbuminuria. The systolic blood pressure $(\mathrm{SBP}) \geq 140 \mathrm{mmHg}$ or diastolic BP (DBP) $\geq 90 \mathrm{mmHg}$ at baseline; microalbuminuria was defined as urinary albumin excretion rate (UAER) of $20-200 \mu \mathrm{g} / \mathrm{min}$ or 24 -h urine protein (24h-UP) 30-300 mg. macroalbuminuria was defined as UAER $\geq 200 \mu \mathrm{g} / \mathrm{min}$ or $24 \mathrm{~h}-$ $\mathrm{UP} \geq 300 \mathrm{mg}$ for the same specimens) 3) study treatment: studies comparing ACEIs treatment with CCBs treatment and having the outcomes of microalbuminuria or macroalbuminuria. The exclusion criteria were as follows: 1) studies failing to report the mean value and SD of the primary efficacy outcome 2) studies including patients with kidney disease secondary to causes other than diabetes 3) studies including patients with an 
active kidney transplant, undergoing kidney transplantation or undergoing dialysis.

\section{Data Extraction}

Two investigators were responsible for extracting the data independently from each included RCT: first author's name, year of publication, mean age of participants, type of diabetes among participants, definition of microalbuminuria, BP categories of participants, intervention(s) prescribed (with dosage levels), follow-up period (in months), the outcome of SBP, DBP, UAER, $24 \mathrm{~h}-\mathrm{UP}, \mathrm{GFR}$ and adverse events. The main outcomes given with median and range were estimated as the Mean and Standard Deviation (13).

\section{Quality Assessment}

The quality of the studies was evaluated independently by two members of our team as described in the Cochrane Handbook for Systematic Reviews of Interventions. We assigned values of low, unclear or high risk of bias to the following domains: random sequence generation, allocation concealment, blinding of participants and personnel, blinding of outcome assessment, incomplete outcome data, selective reporting and other biases. Disagreements were resolved by consensus.

\section{Outcome}

Our team extracted data on the following outcomes: 1) primary outcomes: urinary protein measured as UAER $(\mu \mathrm{g} / \mathrm{min})$ and $24-\mathrm{h}$ UP (mg/24 h); 2) secondary outcomes: renal function measured as GFR $\left.\left(\mathrm{ml} / \mathrm{min} / 1.73 \mathrm{~m}^{2}\right) ; 3\right)$ adverse events (AEs).

\section{Sensitivity Analyses}

Sensitivity analyses were conducted by excluding low-quality studies based on descriptions of randomization, allocation concealment, blinded assessment of outcomes to compare the change of results.

Statistical analysis
For direct meta-analysis, the intervention of interest was ACEIs versus CCB therapy. The Q test and $\mathrm{I}^{2}$ statisticwere used to assess the presence and degree of heterogeneity. If heterogeneity was present or $\mathrm{I}^{2}>30 \%$, the random effect model was applied, otherwise, the fixed-effects model was used. Dichotomous data were presented as risk ratios (RRs), with 95\% confidence intervals (Adverse effects). Weighted mean difference (WMD) was used for continuous outcomes (including SBP and DBP, GFR, UAER) along with their corresponding 95\% confidence intervals (CIs).

All statistical analyses were performed using Review Manager (RevMan), version 5.3 (Cochrane Collaboration, Oxford, UK). $P<0.05$ was considered statistically significant, except for the test of heterogeneity where $P<0.1$ was used. These values were captured as the mean change from baseline to follow-up (with mean $\pm S D$ ). The mean changes were calculated by subtracting the baseline values from the final values. Additionally, the standard deviations of the mean changes $(\mathrm{SD}(\mathrm{C}))$ were calculated according to the follow- formula: $\mathrm{SD}(\mathrm{C})=\sqrt{\mathrm{SD}}(\mathrm{A})^{2}+\mathrm{SD}(\mathrm{B})^{2}-(2 \times \mathrm{R} \times \mathrm{SD}(\mathrm{A}) \times$ $\mathrm{SD}(\mathrm{B}))$ We assumed a pre-post study correlation $\mathrm{R}$ of 0.5 to get an estimate of the mean change in $\mathrm{SD}(\mathrm{C})$.

\section{Ethical approval}

This article does not contain any studies with human participants or animals performed by any of the authors.

\section{Results}

\section{Study selection}

Overall, 686 papers were retrieved, of which198 duplicate papers were excluded. 467 papers were subsequently excluded based on review of title and abstract. Eight papers were subsequently excluded based on full-text review according to the inclusion and exclusion criteria. Six papers could not get data for extraction mean and SD. Seven papers with a total of 430 patients were included in this meta-analysis (Table 1). 
Table 1: Characteristics of trials included in this meta-analysis

\begin{tabular}{|c|c|c|c|c|c|c|}
\hline Studies & $N(T / C)$ & $\operatorname{Age}(y r)$ & $\begin{array}{c}\text { Diabetic } \\
\text { type }\end{array}$ & $\begin{array}{c}\text { Albuminuria } \\
\text { definition }\end{array}$ & Main intervention & $\begin{array}{l}\text { Follow up } \\
\text { (months) }\end{array}$ \\
\hline R.Romero $^{15}$ （1992） & $\begin{array}{c}20 \\
(10 / 10)\end{array}$ & $55.4 \pm 8.6$ & type2 & $24 \mathrm{~h}-\mathrm{UP}>500 \mathrm{mg}$ & $\begin{array}{c}\text { catopril: } 60 \pm 17.5 \mathrm{mg} / \text { day; } \\
\text { nifedipine: } 40 \\
\mathrm{mg} / \text { day }\end{array}$ & 6 \\
\hline $\begin{array}{l}\text { Kirsten Nørgaard }{ }^{16} \\
\text { (1993) }\end{array}$ & $\begin{array}{c}15 \\
(7 / 8)\end{array}$ & $\begin{array}{l}\mathrm{T}: 43 \pm 6 \\
\mathrm{C}: 42 \pm 8\end{array}$ & type1 & 24h-UP>300mg & $\begin{array}{l}\text { Spirapril: } 6 \mathrm{mg} / \text { day }+ \text { fursemide; } \\
\text { Isradipine: } 5 \mathrm{mg} / \text { day }+ \text { fursemide }\end{array}$ & 6 \\
\hline $\begin{array}{l}\text { Raffaele } \\
\text { De Cesaris } \\
(1996)\end{array}$ & $\begin{array}{c}46 \\
(24 / 22)\end{array}$ & $\begin{array}{c}\mathrm{T}: 54 \pm 5.7 \\
\mathrm{C}: 56.0 \pm 4.8\end{array}$ & $\begin{array}{l}\text { type } 1 \\
\text { type } 2\end{array}$ & $\begin{array}{c}\text { UAER:30-300 } \\
\mu \mathrm{g} / \mathrm{min}\end{array}$ & $\begin{array}{l}\text { Benazepril: } \\
\text { 10mg/day; } \\
\text { Nicardipine: } \\
\text { 20mg/day }\end{array}$ & 6 \\
\hline $\begin{array}{l}\text { Mario Velussi }{ }^{18} \\
(1996)\end{array}$ & $\begin{array}{r}18 \\
(9 / 9)\end{array}$ & $\begin{array}{l}T: 55 \pm 2 \\
C: 56 \pm 4\end{array}$ & type2 & $\begin{array}{c}\text { UAER:20-200 } \\
\mu \mathrm{g} / \mathrm{min}\end{array}$ & $\begin{array}{c}\text { Cilazapril:2.5-5 } \\
\text { mg/day+thiazide or furo- } \\
\text { Semide; } \\
\text { Amlodipine:5-10 } \\
\text { mg/day+thiazide or furosemide }\end{array}$ & 36 \\
\hline $\begin{array}{l}\text { B L Salako }{ }^{19} \\
\text { (2002) }\end{array}$ & $\begin{array}{c}30 \\
(15 / 15)\end{array}$ & $\begin{array}{l}\mathrm{T}: 58.7 \pm 5.7 \\
\mathrm{C}: 58.5 \pm 8.4\end{array}$ & type2 & $24 \mathrm{~h}-\mathrm{UP}>300 \mathrm{mg}$ & $\begin{array}{c}\text { Lisinopril5-40 } \\
\text { mg/day+furosemide; } \\
\text { Lacidipine2-8 } \\
\text { mg/day+furosemide }\end{array}$ & 3 \\
\hline $\begin{array}{l}\text { M.Dalla Vestra }{ }^{20} \\
2004\end{array}$ & $\begin{array}{r}180 \\
(89 / 91)\end{array}$ & $\begin{array}{l}\text { T: } 60 \pm 7 \\
\text { C: } 58 \pm 7\end{array}$ & type2 & $\begin{array}{l}\text { UAER:20-200 } \\
\mu \mathrm{g} / \mathrm{min}\end{array}$ & $\begin{array}{c}\text { ramipril:5-10 } \\
\text { mg/day } \\
\text { lercanidipine: } 10-20 \\
\text { mg/day }\end{array}$ & 13 \\
\hline $\begin{array}{l}\text { Roberto Fogari } 21 \\
2005\end{array}$ & $\begin{array}{c}121 \\
(61 / 60)\end{array}$ & $\begin{array}{l}\text { T: } 59.9 \pm 7 \\
\text { C: } 60.6 \pm 6\end{array}$ & type2 & 24h-UP:30-300mg & $\begin{array}{l}\text { lisinopril:10-20 } \\
\text { mg/day; } \\
\text { manidipine:10-20 } \\
\text { mg/day } \\
\end{array}$ & 24 \\
\hline
\end{tabular}

\section{Quality assessment}

The risk of bias in each study was assessed using the criteria recommended by the Cochrane Handbook for Systematic Review of Interven- tions. Only one trial reported random sequence generation (14). One trial reported the method to generate the allocation sequence (15) (Fig. 1A and B).

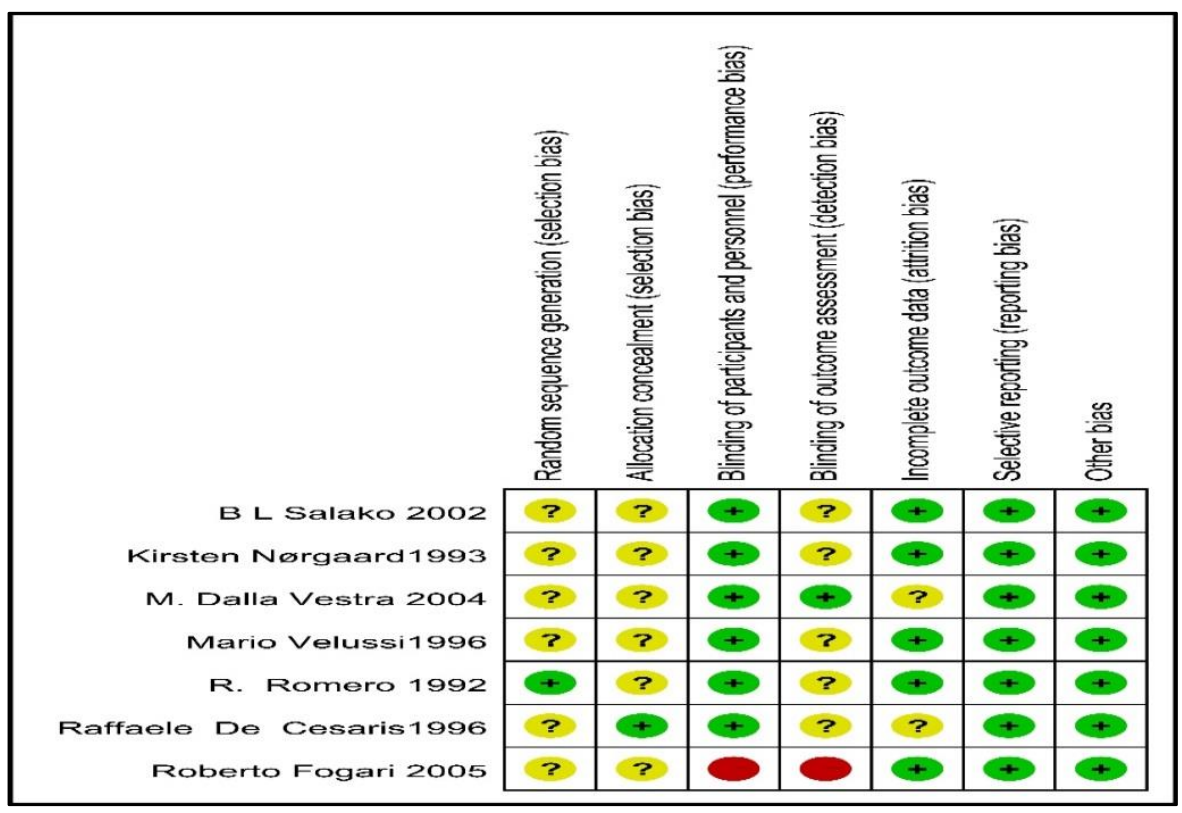

Fig. 1 A: Risk-of-Bias Summary 


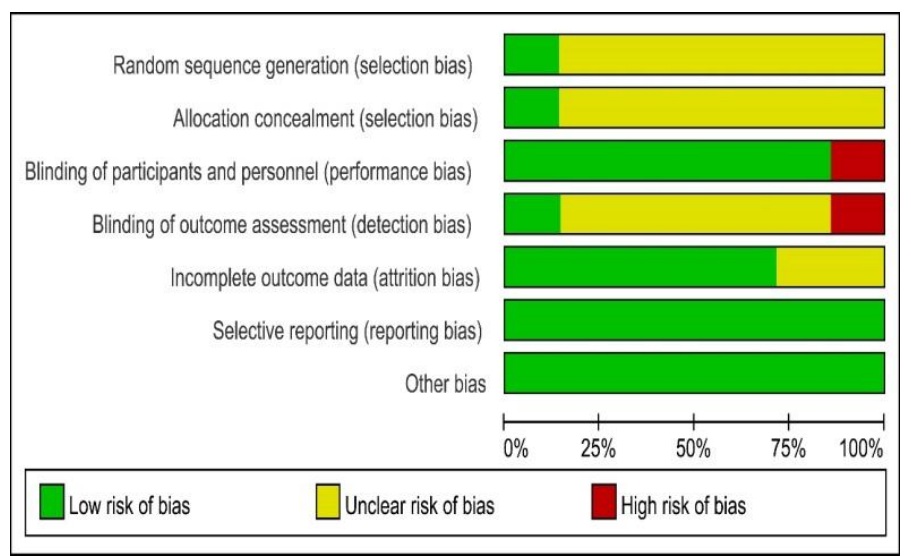

Fig. 1B: Risk-of-Bias Graph of bias

Systolic blood pressure and diastolic blood pressure

Seven studies were included that compared the effect of ACEIs with CCBs on changing the SBP and DBP. There were no differences in the degree of change of SBP (MD=1.05 mmHg; 95\% CI: -0.97 to $3.08 ; P=0.31)$. The treatment effects were homogeneous $\left(P=0.85, \mathrm{I}^{2}=0 \%\right)$. Meanwhile, there were no differences in the degree of change of DBP $(\mathrm{MD}=-0.34 \mathrm{mmHg} ; 95 \% \mathrm{CI}$ : 1.2 to $0.51 ; P=0.43)$. There was no significant heterogeneity among the seven studies $(\mathrm{P}=0.50$, $\mathrm{I}^{2}=0 \%$ ).

\section{4h-Urinary protein or Urine albumin excre- tion rate}

Four trials (14,16-18) in our analysis compared the effect of ACEIs with CCBs on reducing 24hour urinary protein with CCBs. The metaanalysis suggested that there were no differences in the degree of change of $24 \mathrm{~h}$-proteinuria levels $(\mathrm{SMD}=-0.26 ; 95 \% \mathrm{CI}:-0.55$ to $0.03 ; P=0.08$, Fig.2). The test for heterogeneity was low $\left(P=0.73, \mathrm{I}^{2}=0 \%\right)$. Three papers $(15,19,20)$ reported urine albumin excretion rate. The change in urine albumin excretion rate related outcome was not significantly different between the two treatment arms $(\mathrm{MD}=1.91 \mu \mathrm{g} / \mathrm{min} ; 95 \% \mathrm{CI}:-10.3$ to $14.12 ; P=0.76$, Fig.3). We recorded no significant interstudy heterogeneity among the 3 studies $\left(P=0.88, \mathrm{I}^{2}=0 \%\right)$.

\section{Glomerular filtration rate}

Four trials $(14-16,19)$ investigate the GFR for a total of 99 participants. There were no differences in the degree of change of GFR between ACEIs group and CCBs group (SMD $=0.01 ; 95 \%$ CI: -0.38 to $0.41 ; P=0.95$, Fig.4). Heterogeneity between the 4 studies was not significant $\left(P=0.95, I^{2}=0 \%\right)$.

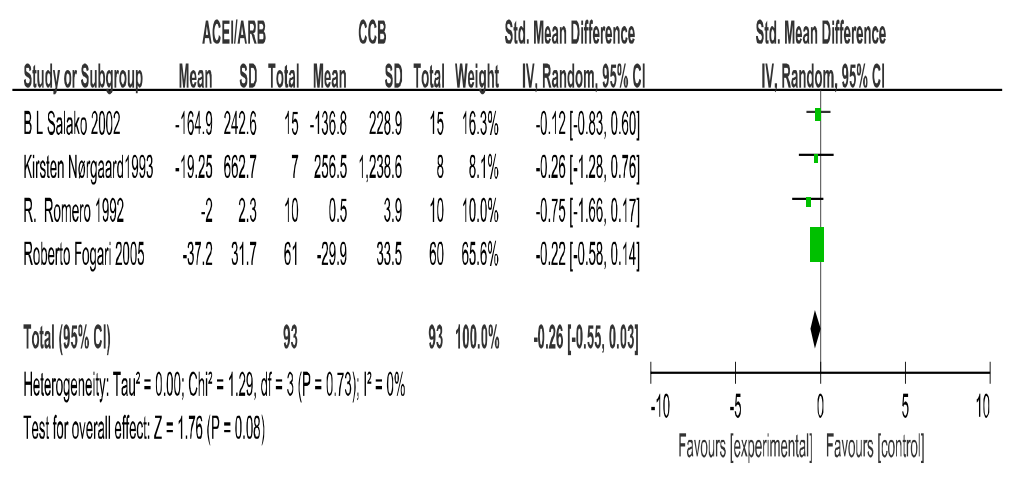

Fig. 2: The changes in 24h-urine protein (24h-UP): Forest Plot of Comparison ACEI/ARB Versus CCB Only 


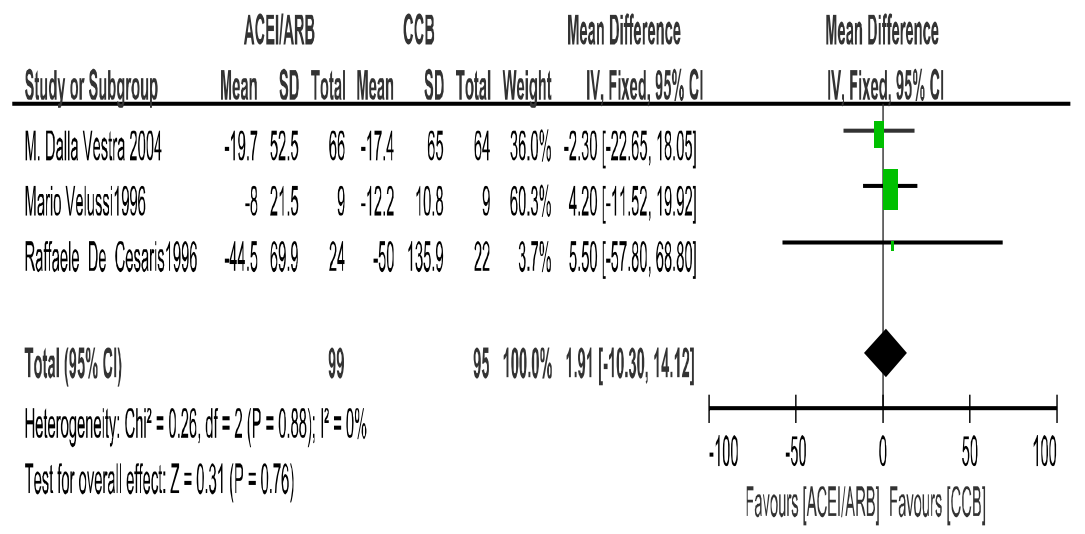

Fig. 3: The changes in urinary albumin excretion rate (UAER): Forest Plot of Comparison ACEI/ARB Versus CCB Only

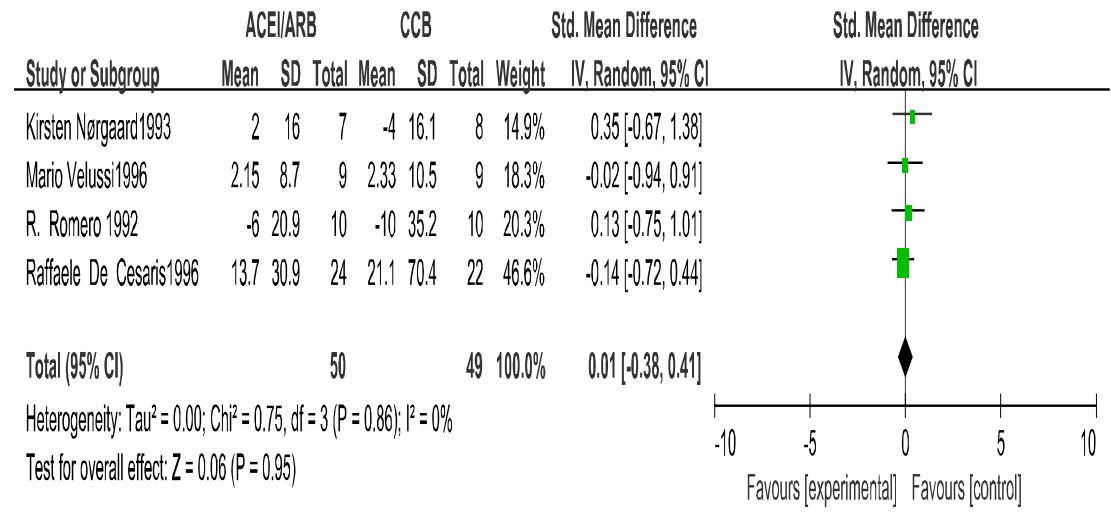

Fig. 4: The changes in glomerular filtration rate (GFR): Forest Plot of Comparison ACEI/ARB Versus CCB Only

Primary safety endpoint: adverse events

Three papers $(16,18,20)$ report the adverse events. A fixed effects model was used to compile the results because heterogeneity was small among the 4 studies $\left(\mathrm{I}^{2}=0\right)$. There was no significant difference in the risk of adverse reactions between ACEIs group and CCBs group $(\mathrm{RR}=1.18$; $95 \%$ CI: 0.61 to 2.28 ; $P=0.61$, Fig. 5).

\begin{tabular}{|c|c|c|c|c|}
\hline Study or Subgroup & $\begin{array}{c}\text { ACEls } \\
\text { Events Toter }\end{array}$ & $\begin{array}{l}\text { CCBS } \\
\text { Events Total Weight }\end{array}$ & $\begin{array}{c}\text { Risk Ratio } \\
\text { M.H, Fixed, 95\% C }\end{array}$ & $\begin{array}{c}\text { Risk Ratio } \\
\text { M.H, Fixed, 95\% Cl }\end{array}$ \\
\hline Kirsten Nergaardid1993 & 0 & $1710.2 \%$ & $0.33[0.02,7.02]$ & \\
\hline M. Dalla Vestra 2004 & 149 & $10 \quad 8969.1 \%$ & $1.37[0.64,2.22]$ & \\
\hline Roberto Fogari 2005 & 36 & $3 \quad 60 \quad 20.7 \%$ & $0.98[0.21,4.68]$ & \\
\hline Total $(95 \%$ Cl) & 15 & $156 \quad 100.0 \%$ & $1.18[0.61,2.28]$ & \\
\hline Total events & 17 & 14 & & \\
\hline $\begin{array}{l}\text { Heterogenenty: Chi' }=0 \text {. } \\
\text { Test for overall effect: } Z\end{array}$ & $\begin{array}{l}36, d f=2 p=0 \\
=0.50(P=0.6\end{array}$ & ${ }^{2}=0 \%$ & & $\begin{array}{lllll}0.01 & 0.1 & 1 & 10 & 100 \\
& \text { Favours [ACEIs] Favours [CCBS] }\end{array}$ \\
\hline
\end{tabular}

Fig. 5: The changes in adverse reaction (ADR): Forest Plot of Comparison ACEI/ARB Versus CCB Only 
Sensitivity analysis

Removal of unblinded, low-quality studies from our analysis did not alter the results for the primary endpoint significantly.

\section{Discussion}

Diabetic nephropathy (DN), a common complication in patients with diabetic, is characterized by hypertension, macroalbuminuria, microalbuminuria and abnormal renal function (21). The pathophysiological mechanisms in the development of DN are very complex. They may include glomerular hyperfiltration, glomerular and tubular epithelial hypertrophy, microalbuminuria. Activation of rennin-angiotensin system is involved in almost all the steps in the development of DN $(22,23)$. Drugs acting on the Renin-AngiotensinAldosterone System (RAAS) play a crucial role in the therapeutic regimen to prevent DN (24). Calcium channel blockers (CCBs) are recommended to add to the therapeutic regimen (10). It may act predominantly by relaxing the afferent glomerular arteriole, increasing intraglomerular pressure. ACEIs and CCBs have similar beneficial effects on reducing the progression of diabetic nephropathy $(25,26)$. However, ACEIs have better effects on reducing the progression of diabetic nephropathy (27). This meta-analysis tries to further compare the effectiveness and safety of ACEIs with CCBs on treating diabetic nephropathy.

Our meta-analysis showed that ACEIs are not superior to $\mathrm{CCBs}$ in reducing SBP, DBP, GFR, UAER, and 24-h UP in DN patient with hypertension. Regarding safety, this meta-analysis showed that ACEIs group and CCBs group have similar incidence of adverse events. Vejakama (28) suggests a consistent reno-protective effect of ACEIs and angiotensin II receptor blocker (ARBs) over other antihypertensive drug in type 2 diabetes on the risk ratio of the outcome of albuminuria regression, microvascular complications, serum creatinine doubling, macroalbuminuria, microalbuminuria and ESKD but not the change of UAER and 24-h UP which are the main screening indicators of DN. Our result was the first time to compare ACEIs with CCBs in changing the UAER and 24-h UP. The different results of the two studies may be due to different observed indicator, baseline of BP and treatment duration. Lisinopril reduced albuminuria, but also GFR, to a greater extent than nisoldipine did in hypertensive IDDM patients with diabetic nephropathy during the first year of treatment (30). ACEIs and CCBs equally reduce the progression of nephropathy in hypertensive type 2 diabetics $(26,29,30)$. It was consistent with our results, but these studies are not included in our meta-analysis due to unreported urinary albumin excretion or lack of the mean and SD of urinary albumin excretion.

There are some limitations to our study. Firstly, the studies included in our meta-analysis are relatively small, so do the population. Secondly, the methodological quality of the included studies was not very high. The methods of randomization were not clear in all the trials. Thirdly, drug effectiveness may vary with different follow up duration and different diabetic types, a subgroup analysis according to follow up duration and diabetic types would provide valuable insight. Unfortunately, our analysis was not possible with enough available data. Lastly, the CCBs are all calcium channel blocker of dihydropyridine, whether other kinds of CCBs have the same function remains unknown.

\section{Conclusion}

Patients with hypertension and diabetic nephropathy derive similar benefit from ACEIs therapy and CCBs therapy on reducing BP, GFR, UAER and $24 \mathrm{~h}-\mathrm{UP}$. The incidences of adverse reaction between the two therapies are similar. However, the studies included in our meta-analysis are relatively small, we could not do a subgroup analysis according to follow up duration and diabetic types, so further large, multi-center, high-quality studies are necessary to investigate.

\section{Ethical considerations}

Ethical issues (Including plagiarism, informed consent, misconduct, data fabrication and/or fal- 
sification, double publication and/or submission, redundancy, etc.) have been completely observed by the authors.

\section{Acknowledgements}

We would like to thank B L Salako for providing original paper for this analysis that we could not download.

\section{Conflict of interest}

The authors declare that they have no competing interests.

\section{References}

1. Said SM, Nasr SH (2016). Silent diabetic nephropathy. Kidney Int, 90:24-26.

2. Afkarian M, Sachs MC, Kestenbaum B (2013). Kidney disease and increased mortality risk in type 2 diabetes. J Am Soc Nephrol, 24: 302-308.

3. Brenneman J, Hill J, Pullen S (2016). Emerging therapeutics for the treatment of diabetic nephropathy. Bioorg Med Chem Lett, 26:4394 4402.

4. National Kidney Foundation (2002). K/DOQI clinical practice guidelines for chronic kidney disease: evaluation, classification and stratification. Am J Kidney Dis, 39: S1-S266.

5. Perkins BA, Ficociello LH, Silva KH et al (2003). Regression of microalbuminuria in type 1 diabetes. NEngl J Med, 348:2285-2293.

6. Kota SK, Meher LK, Jammula S et al (2012). ACE inhibitors or ARBs for diabetic nephropathy: The unrelenting debate. Diabetes Metab Syndr, 6:215-217.

7. Molitch ME, Adler AI, Flyvbjerg A et al (2015). Diabetic kidney disease: a clinical update from Kidney Disease: Improving Global Outcomes. Kidney Int, 87(1):20-30.

8. Umanath K, Lewis JB (2018). Update on Diabetic Nephropathy: Core Curriculum. Am J Kidney Dis, 71(6)884-895.

9. Stephen Thomas, Gian Carlo Viberti (2010). Diabetic Nephropathy. Medicine, 38: 639-643.

10. Guorong Ma, Terri J. Allen, Mark E. Cooper (2004). Calcium channel blockers, either amlodipine or mibefradil, ameliorate renal injury in experimental diabetes. Kidney Int, 66(3):1090-8.

11. Slataper R, Vicknair N, Sadler R, Bakris GL (1993). Comparative effects of differrent antihypertensive treatments on progression of diabetic renal disease. Arch Intern Med, 153:973980.

12. Fukumoto S,Ishimura E, Motoyama $\mathrm{K}$ et al (2012). Antialbumin-uric advantage of cilnidipine compared with L-type calcium channel blockers in type 2 diabetic patients with normoalbuminuria and microalbuminuria. Diabetes Res Clin Pract, 97:91-98.

13. Hozo SP, Djulbegovic B, Hozo I (2005). Estimating the mean and variance from the median, range, and the size of a sample. BMCMed Res Methodol, 5:13.

14. Romero R, Salinas I, Lucas A et al (1992). Comparative effects of captopril versus nifedipine on proteinuria and renal function of type 2 diabetic patients. Diabetes Res Clin Pract, 17:191-198.

15. De Cesaris R, Ranieri G, Andriani A et al (1996). Effects of benazepril and nicardipine on microalbuminuria in normotensive and hypertensive patients with diabetes. Clin Pharmacol Ther, 60: 472-478.

16. Nørgaard K, Jensen T, Christensen $P$ et al (1993). A Comparison of Spirapril and Isradipine in Patients with Diabetic Nephropathy and Hypertension. Blood Press, 2(4): 301308.

17. Salako BL, Finomo FO, Kadiri S et al (2002). Comparative effect of lisinopril and lacidipine on urinary albumin excretion in patients with type 1 diabetic nephopathy. Afr J Med Med Sci, 31:53-57.

18. Fogari R, Mugellini A, Zoppi A, et al (2005). Effect of successful hypertension control by manidipine or lisinopril on albuminuria and left ventricular mass in diabetic hypertensive patients with microalbuminuria. Eur J Clin Pharmacol, 61:483-490.

19. Velussi M, Brocco E, Frigato F et al (1996). Effects of cilazapril and amlodipine on kidney function in hypertensive NIDDM patients. Diabetes, 45: 216-222.

20. Dalla Vestra M, Pozza G, Mosca A et al (2004). Effect of lercanidipine compared with ramipril on albumin excretion rate in hypertensive type 2 diabetic patients with micioalbuminu- 
ria: DIAL study (Diabete, lpertensione, Albuminuria, Lercanidipina). Diabetes Nutr Metab, 17: 259-266.

21. Ahmad J (2015). Management of diabetic nephropathy: Recent progress and future perspective. Diabetes Metab Syndr, 9: 343-358.

22. Rahimi $Z$ (2016). The Role of Renin Angiotensin Aldosterone System Genes in Diabetic Nephropathy. Can J Diabetes, 40(2):178-183.

23. Vinod PB (2012). Pathophysiology of diabetic nephropathy. Clin Queries Nephrol, 1: 121-126.

24. Parving HH, Andersen S, Jacobsen P et al (2004). Angiotensin receptor blockers in diabetic nephropathy: renal and cardiovascular end points. Semin Nephrol, 24:147-157.

25. Tarnow L, Rossing P, Jensen C et al (2000). Long-Term reno-protective effect of nisoldipine and lisinopril in type 1 diabetic patients with diabetic nephropathy. Diabetes Care, 23:1725-1730.

26. Ruggenenti P, Mosconi L, Bianchi L, et al (1994). Long-Term treatment with either enalapril or nitrendipine stabilizes albuminuria and in- creases glomerular filtration rate in noninsulin-dependent diabetic patients. Am J Kidney Dis, 24:753-761.

27. Rossing P, Tarnow L, Boelskifte S, et al (1997). Differences between nisoldipine and lisinopril on glomerular filtration rates and albuminuria in hypertensive IDDM patients with diabetic nephropathy during the first year of treatment. Diabetes, 46:481-487.

28. Vejakama P, Thakkinstian A, Lertrattananon D et al (2012). Reno-protective effects of reninangiotensin system blockade in type 2 diabetic patients: a systematic review and network meta-analysis. Diabetologia, 55: 566-578.

29. Fogari R, Zoppi A, Corradi L et al (1999). Longterm effects of ramipril and nitrendipine on albuminuria in hypertensive patients with type II diabetes and impaired renal function. $J$ Hum Hypertens, 13: 47-53.

30. Baba S, J-MIND Study Group (2001). Nifedipine and enalapril equally reduce the progression of nephropathy in hypertensive type 2 diabetics. Diabetes Res Clin Pract, 54:191-201. 